\title{
Workplace Perceptions of Older Workers and Implications for Job Retention'
}

\section{Kjetil Frøyland ${ }^{2}$}

Researcher/PhD, Work Research Institute, Oslo Metropolitan University, Norway

\section{Hans Christoffer Aargaard Terjesen}

Researcher/PhD-student, Work Research Institute, Oslo Metropolitan University, Norway

\begin{abstract}
Older workers' opportunities for late careers are influenced by employer attitudes and willingness. Nordic managers seem unwilling to hire and retain older persons. In this article, we explore Norwegian workplace perceptions of older workers and the way they are positioned at the workplace. We base this article on qualitative interviews with managers and both union and HR-representatives from 19 companies. Previous research has linked this unwillingness to stereotypes and ageism among employers. We find that the perceptions of older workers do not rest only on stereotypes and ageism, but also on concrete experiences of older workers and processes or mechanisms of positioning and polarization that sometimes occur within the workplace. These actors perceive older workers as a heterogeneous group. We argue that these perceptions may lead to ambivalence towards older workers as a group, and in how to handle them individually. Qualified and available support and flexible strategies are needed.
\end{abstract}

\section{KEYWORDS}

Job retention / leadership / retirement / senior policy / work inclusion

\section{Introduction}

everal researchers have concluded that older workers' opportunities for late careers, and the restrictions they potentially face, are to a large degree shaped by their employers' attitudes and willingness to retain older staff, and to hire older workers (Egdell et al. 2018; Hermansen 2016, p. 29). According to Henkens and van Dalen, employers are 'key players in defining the opportunities for retirement as well as the opportunities for working longer' (2012, p. 25).

The Nordic welfare states have been described as some of the world's most generous (Esping-Andersen 1990), and Salomon makes the claim that attitudes towards older workers seem to be more positive in the Nordic countries 'compared with several countries in Southern and Eastern Europe' (2012, p. 2). In both the Nordic and other countries however, managers seem reluctant to hire applicants in their late 50s (Blomé et al. 2018; Conen et al. 2012; Solem 2016).

Several scholars relate this reluctance among employers to concepts such as 'stereotypes', 'age discrimination' or 'ageism' (Ayalon \& Tesch-Römer 2017; Egdell et al.

\footnotetext{
${ }^{1}$ You can find this text and its DOI at https://tidsskrift.dk/njwls/index.

${ }^{2}$ Corresponding author: kjetil.froyland@oslomet.no.
} 
2018; Furunes \& Mykletun 2011; Henkens 2010; Kadefors \& Hanse 2012; Kroon et al. 2018). 'Age stereotyping' has been defined as 'a simplified, undifferentiated portrayal of an age group that is often erroneous, unrepresentative of reality, and resistant to modification' (Chiesa et al. 2016, p. 1153; Schulz 2006) and is often referred to as part of the wider concept of 'ageism'. For instance, Ayalon and Tesch-Römer recently defined 'ageism' as 'stereotypes, prejudice, or discrimination against (but also in favor of) people because of their chronological age' (Ayalon \& Tesch-Römer 2017, p. 1). They further describe 'ageism' as a rather complex domain that includes cognitive, behavioral and emotional manifestations. Such attitudes and stereotypes may be communicated to employers in different ways, for instance through media (Kroon et al. 2018), or existing ideologies (Martin et al. 2014).

One major viewpoint in these studies is that employers hesitate to hire or retain older workers because of the presence and influence from 'ageism' and 'age stereotypes'. This view is supported by several studies that show that older workers can perform well at work and represent important and vital competence for the companies (See for instance: Kroon et al. 2018; Taylor \& Earl 2016). Older workers therefore suffer from discrimination because they are 'denied' access or prolonged access to work life because of their age ('age discrimination').

These concepts are widely supported within the research literature on job retention of older workers. However, both concepts remain unclear as to whether reluctance among employers could also have other and perhaps more 'concrete' reasons and what such reasons in fact could be. For instance, some scholars have pointed out that stereotypes are only one out of several influences on employers' perceptions of older workers (Kroon et al. 2018; Taylor \& Earl 2016). Several studies suggest that attitudes and perceptions towards older workers among employers are rather mixed (Egdell et al. 2018; Henkens 2010; Kadefors \& Hanse 2012; Kroon et al. 2018). Where some of these studies claim that negative perceptions dominate (Conen et al. 2012), others are more neutral (Henkens 2010). Furthermore, Furunes and Mykletun have suggested that workplace or organizational factors such as 'culture or the development of actual capabilities influence how managers perceive the older workers' (2011, p. 188), and that employer perceptions should not be conceived as stereotypes because they are not as persistent and general as proposed by other scholars in the field. They call for more in-depth research 'addressing the relationships between stereotypes, actual performance and behavior, and managers perceptions in relation to age at the workplace' (Furunes \& Mykletun 2011, p. 188). Henkens et al. (2017) also call for a better understanding of employer behavior.

Previous research has documented the presence of stereotypes and ageism among employers and linked the unwillingness to hire or retain older workers to these concepts. However, some studies suggest that there could also be other reasons for employers' hesitance and call for better understanding of the employer behavior and the role of the workplace. In this article, we will contribute new knowledge to this field by exploring what reasons employer perceptions and behavior may have and whether there may be also other reasons or mechanisms in play than the presence of stereotypes and ageism. We will do this by qualitatively studying experiences and observations from Norwegian employers, HR-representatives and union representatives of how older workers perform and behave at the workplace. We have applied a 'workplace perspective' where we aim to investigate perceptions among these three informant groups. We are interested in their thoughts about older workers and what goes on at the workplace in relation to

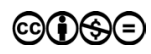


them; their performance at work, possible roles they take, and processes or mechanisms in play at workplaces where older workers are involved. Several definitions of the term 'mechanism' exist in social science studies (Hedström \& Ylikoski 2010). For the purpose of this article, we will adopt the definition of Bunge (2004): 'A mechanism is a process in a concrete system that is capable of bringing about or preventing some change in the system.' Our major research questions are:

1. What kind of observations and experiences of older workers' performance and behavior do employers, HR- and union-representatives in Norwegian companies have?

2. What kind of perception or general understanding of older employees and their behavior in the workplace do these experiences contribute to?

3. What possible mechanisms behind workplace perceptions and the unwillingness of employers to hire or retain older workers do these observations imply, and what barriers to longer work-careers do they represent?

We base our analysis of employer's, HR- and union-representative's descriptions of older workers and the roles they play in the work environments, on 37 qualitative interviews that we conducted in 19 Norwegian companies in 2016 and 2017.

The article is structured in five major sections. First, we present some theoretical perspectives adopted from different literature that we use as an analytical framework for the further presentation and analysis. We sort and present the previous research literature on the labor market participation of older workers according to this framework. Second, we present the method and analysis. Third, we outline the findings more in detail and link the empirical observations to major concepts of this article. Fourth, we discuss how employer behavior on job retention of older workers can be understood based on our findings. Finally, we sum up and conclude.

\section{Background and theoretical perspectives}

Although studies on active labor market policies (ALMPs) does not focus explicitly on older workers, looking rather at the inclusion and retention in work life of jobless and vulnerable groups in general, the focus on employment and job retention of groups facing difficulties in finding and holding a job, makes these perspectives relevant for this article. Within the ALMP-literature, approaches towards labor market inclusion of jobless groups have been sorted in two kinds of perspectives: a 'supply-side' and a 'demandside' perspective (Frøyland et al. 2018a; Ingold \& Stuart 2015):

1) The 'supply-side' perspective focuses mainly on individuals in need of a job and aims to explore and enhance the ability and capacities of the individuals themselves to find and hold a job. Approaches affiliated with this perspective hold the abilities and characteristics of the individual as vital causes of inclusion or exclusion, and therefore seek to develop individual employability.

2) The 'demand-side' perspective concentrates on employers and workplaces, aiming to activate employers and to understand the role they play in such inclusion. Approaches based on this perspective explain inclusion or exclusion based on characteristics and qualities within the workplaces and the employers and seek to force 
or encourage them to include/keep employees that for various reasons strive to find and/or hold onto a job.

We will use these perspectives as analytical lenses in this article and sort the research literature on labor market participation of older workers accordingly.

\section{Individual factors and supply-side perspectives}

Our reading of literature on the work-retention of older workers reveals that individual factors and perspectives are much explored within this stream of research as factors with relevance for employers' perceptions of older workers. Studies in this field have found that older workers score high on experience, trust and independence, compared to younger workers, while their scores are lower on health, ICT skills, productivity, flexibility, creativity, ability to learn, openness to new ideas and other cultures (see for instance Conen et al. 2012; Kadefors \& Hanse 2012). Other researchers frame such characteristics in terms of higher levels of warmth/soft skills in older workers, and lower scores on competence/hard skills (Kroon et al. 2018; Martin et al. 2014). Some studies, for instance, refer to older workers as mentors or as more supportive towards younger colleges (Egdell et al. 2018; Kadefors \& Hanse 2012).

Some studies have focused on employer attitudes and understandings of their older employees. Nevertheless, many of them seem to simply contribute to understandings of 'the older employee', and not to further develop understandings of employers' perceptions related to a focus on the workplace. One such example is Harris et al. (2017) who find both positive and negative stereotypes and perceptions among employers, but still end up discussing their findings within a supply-side framework. For instance, they describe employers' perceptions of older workers in terms of positive perceptions (reliability, experience, knowledge, commitment and/or loyalty) as well as the employer's view of older workers as 'warmer workers' (more friendly, empathetic, kind) than younger workers. Among the negative perceptions, they find lower levels of competence, decreased performance capacity, less adaptability, less flexibility and less willingness to change. According to Harris et al., some employers do not see older workers as valuable assets in 'resolving future labor market shortages', but rather as 'poor investments' and as less keen to undertake required (re)training. Furunes and Mykletun also add to this same vein of research when they state that managers often assess ageing as contributing 'to increased managerial and interpersonal skills, creative problem solving capacities and work moral', (2011, p. 173) while at the same time stating that older workers have a 'reduced learning capacity, and reduced basic functions'. Herlofsen and Hellevik (2019) further exemplify this thinking with their research [on studies of data from the Norwegian Life Course, Ageing and Generation Study (NorLAG)] suggesting that older workers do not perceive themselves as more tired than younger colleagues, rather the opposite.

Other studies in a similar manner have described older workers as a heterogeneous group (Henkens 2010; Kadefors \& Hanse 2012). Wainwright et al., for instance, suggest that older workers are a heterogeneous group, differentiated not only by issues such as gender and social class, 'but also by different experiences that accrue across the life course' (Wainwright et al. 2018, p. 21). Wainwright et al. thus seem to suggest that the individual 
difference is something that develops as time goes by and more experience is gained. Some studies have also documented that older persons are more careful than younger (Kadefors \& Hanse 2012).

According to scholars in the field of identity work, individual performance, as outlined in the studies above, should also be related to and understood in light of the local contexts of interaction (LaPointe 2010). Lapointe (2010) and Arvaja (2016), for instance, relate professional performance to the social context in which one takes part and claim that workers 'position' themselves within the work environment in a process of co-construction with the local context. These scholars - although speaking from a different stream of literature - call for a more developed focus on the role of the workplace and how the workplace and the employees interact. Their call is also in line with recent developments within the field of ALMPs where ALMPs have been criticized for being based on a 'supply-side fundamentalism' (Frøyland et al. 2018a; Ingold \& Stuart 2015). Scholars accordingly argue for the necessity of a demand-side approach addressing more explicitly the employers and workplaces.

\section{Workplace and demand-side perspectives}

A demand-side perspective is present in some studies within the field of work retention of older workers. Vigtel, for instance, clearly takes a demand-side perspective when he finds that 'risk-averse firms are more willing to hire senior workers when the minimum legal retirement age is decreased' $(2018$, p. 247). The role of the workplace is also evident in studies such as Van Solinge and Henkens (2017) that found that emotions in older workers were stronger among individuals that have less access to resources, and that anger and anxiety is more prevalent among older workers in more demanding jobs (van Solinge \& Henkens 2017, p. 273). Also, Egdell et al. (2018) involve a demand-side perspective when they find that managers tend to think about employees in terms of individuals rather than their age, and argue that not 'considering the implications of age and ageing on the workplace may mean that support is not put in place to support workers as they get older' ( $p$ 15). They conclude that treating employees' age and fitness for work solely on an individual basis and not utilizing formal plans to manage the workplace for older workers, indicates a 'hands-off approach from management' (p. 16), and a reactive approach (rather than proactive or preventative). Egdell et al. (2018) also claim that employers may find it hard or irrelevant to develop policies that support older workers 'as it is hard to pin down exactly who older workers are, as this may vary from individual to individual, by sector and by job role'. Several other scholars also find a high degree of uncertainty and ambivalence among managers regarding the desirability and feasibility of extending working life (Martin et al. 2014; Wainwright et al. 2018). Martin et al. (2014) suggest flexible and creative approaches to policy and practices that acknowledge the heterogeneity of older workers.

Davies et al. (2018) also contribute in this manner of thinking when they investigate managers' openness to involvement in employee retirement. They show that supervisors can influence retirement decisions in many ways, for instance through opportunities made available through discretionary influence on flexible retirement arrangements, through work climate and culture, and through supervisory social support that 'has been found to increase the likelihood of later retirement' (Davies et al. 2018, p. 1282). 
However, involvement in discussions with seniors can be complex and risky, as direct and overt questions about individuals' retirement intentions may be experienced by employees as discriminatory, Davies et al. further claim. Achieving the appropriate balance in such conversations therefore requires skillful managerial competence. Furthermore, Davies et al. find that the manager's own decision-making environment and the organizational context are important factors, noting that:

Where managers are able to exert discretion in terms of the work-options available, they are more likely to have the confidence to make finely balanced and appropriate judgements which achieve fair and just outcomes for both the individual and the organisation (Davies et al. 2018, p. 1295).

Despite these latter findings, according to our reading, a supply-side focus seems to dominate within research on job retention of older workers investigating perceptions among employers based on an individual-oriented focus. This stream of literature often refers to stereotypes, ageism and age discrimination as pivotal reasons for employer behavior. Some newer studies within this field suggest that a more workplace-oriented approach is necessary to better understand perceptions present at the workplace and employers' unwillingness to hire seniors. Our major impression, however, is that a 'demand-side' focus on work retention of older workers seems so far to be marginally explored within this field.

This article contributes to the further development of a demand-side perspective within the field of age retirement and job retention of older workers by providing new knowledge about workplace perceptions and possible mechanisms behind such perceptions. We will do this by exploring first the observations and perceptions that exist among employers, HR- and union-representatives about older workers and how they behave and interact within workplaces, and then by discussing possible mechanisms behind such perceptions and what kind of challenges such perceptions may impose on employers in order to facilitate job retention of older workers.

\section{Data and method}

The analyses presented here are based on in-depth interviews conducted with managers, HR-personnel and union representatives in 19 work organizations in Norway, during the period from 2016-2017. We have sorted these 19 companies in eight branches/sectors: bank and finance (2), health institutions (hospitals/clinics) (4), service or care (2), transport (bus and boat) (2), industry, energy, construction (3), merchandise and retail (2), technology and research (3), and church (1). The informants were recruited in cooperation with eight Work Life Centers within the Norwegian Labor and Welfare Administration (NAV). Such Work Life Centers exist in each county in Norway, and from 2001 until 2019, one of their tasks has been to support and assist Norwegian workplaces in senior policy issues (Frøyland et al. 2018b). This means that they have provided support and assistance to companies related to issues such as need for support in developing a senior policy in order to be able to keep employees longer in work or related to problems with some of their older workers. However, in conjunction with the renewal and altering of the Norwegian agreement on inclusive work life (the 'IA Agreement') at the 
end of 2018, these senior policy aims were removed from the IA-agreement ${ }^{1}$, and in the new IA-agreement, the role of the Work Life Centers on issues related to senior policy therefore seems more unclear.

Advisors working in these Work Life Centers recruited a number of companies from different branches and in different regions of Norway that according to their knowledge had current or previous experiences with older workers older than 67 years of age. The researchers then chose companies among these suggestions. The advisors made the initial contact with these organizations and provided the researchers with contact information. The informants were top and lower level managers, HR-directors and HRpersonnel, and union/safety delegates. All of them were well experienced in handling or following up employees as professionals within their kind of work organization. Most of them had worked in their present position or similar positions for many years. The recruited informants all had experience with seniors older than 67 years of age.

Data were collected in accordance with multiple case study designs (Yin 2014) and mainly consisted of transcribed, semi-structured qualitative interviews. We interviewed a total of 37 informants (1-4 from each company) utilizing an interview guide containing 60 questions on topics such as work culture, work environment, leadership approaches, work tasks, senior policy and presence of seniors, as well as experiences with the work performance of seniors and their potential support requirements. Each interview lasted 1-2 hours. Whereas some questions were close-ended and easily answered, others were open-ended and often lead to longer reflections. Not all questions were relevant for each informant of each company. For this article, answers on questions covering the observations, experiences and perceptions among the informants about older workers have been selected.

Most of the interviews (31 of 37) were conducted by two researchers. After these interviews, one of the researchers summed up the interview in a draft by writing out the notes from the interviews on each question. The second researcher then read the sum up and revised or added missing information. In cases where the two researchers' notes differed, they re-read their notes and discussed their interpretations so that they reached an agreement.

The major strength of the chosen approach was that our informants had formed a broad picture of relevant experiences within their companies because of their long experience. One weakness was that we interviewed only a few representatives from each company (1-4). Since most of the companies were quite large, our informants' experiences could not cover the full range of relevant experiences related to older employees in the company. As such, we do not have enough information to define or single out the 'company-approach' to these issues. The informants' perceptions - even though representing certain companies within certain branches - therefore should be understood as individual observations and perceptions more than those of 'companies'. Another weakness was that we mainly asked about the informants' general impressions and did not focus systematically on specific cases. This approach may therefore show a bias towards these informants' 'stereotypes' of older employees, rather than broader and more diverse experiences that a more specific approach within each company might have displayed. However, several of the informants provided us with individual and concrete examples.

As this is a qualitative study and the selected companies and their informants are rather few compared to the total population of companies and workplace stakeholders 
in Norway, the selected cases are not representative of the Norwegian (nor Nordic) labor market in a statistical sense. Therefore, we cannot generalize statistically from our findings. However, by recruiting informants from different kinds of companies and branches in different parts of Norway, we have established a variation in sources and contexts from which we have collected data. This variation enables us to better assess the relevance of the informants' observations and experiences by comparing and finding similarities and differences across companies and branches. While this does not enable us to generalize statistically, we argue, just as Yin does (2014) that it is possible to generalize analytically from these observations. This means, for example, that while we cannot decide how often or how common such perceptions are at Norwegian workplaces based on our data, we can provide examples of what kind of perceptions and observations exist at Norwegian workplaces, what kind of challenges they may refer to or represent, and how they can be addressed when they occur.

\section{Analytical approach}

After conducting the interviews, we listened to the recordings, read the interview protocols several times and developed matrices to display relevant data from the 19 companies/cases. We followed an inductive and data-driven approach (Gibbs 2007; Yin 2014). Our aim was not to perform an explicit case-to-case comparison, but to identify experiences and understandings of older employees across cases. First, we listed the informants' descriptions and phrasings about older employees and their behavior at the workplace. We arranged this list according to company and branch. We sorted the informants' descriptions and expressions in different topics or types of descriptions (such as positive or negative, meaning of age, individuality/heterogeneity, role, positioning and polarity). While some of these were descriptions of older workers and their qualities (supply-side perspective), others were perceptions of how the older workers interfered with the work environment and at the workplace (closer to a demand-side perspective). In the finding section below, we exemplify more in detail how we linked the different empirical observations to such types of perceptions or concepts.

The process of analysis thus followed a 'bottom-up' approach with similarities to grounded theory approach (Charmaz 2006). Furthermore, the analysis resembles a variable-oriented, cross-case analysis. In variable-oriented approaches, 'generality is given precedence over complexity' (Ragin 1987, p. 54), where the details of any specific case 'reside behind the broad patterns found across a wide variety of cases' (Miles et al. 2014, p. 102). Variable-oriented, cross-case analysis has been criticized for being poor at handling real complexities and sometimes producing very general or even 'vacuous' findings (Miles et al. 2014, p. 102). However, we focused more on themes than on variables (Thagaard 1999) and our approach therefore should be understood as a 'themeoriented, cross-case analysis'. However, theme-centric analysis has also been criticized as separating data from its original context (Thagaard 1999). Several authors have therefore suggested combinations of variable-oriented and case-oriented, cross-case analysis (Miles et al. 2014; Ragin 1987; Thagaard 1999). The data and the analyses presented in this article form part of a larger research project that includes more detailed discussions and elaborations on and with each of the recruited companies. As such, we had more focus on context than is displayed in this article.

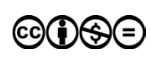


In the presentation of our findings, we first outline the major observations and perceptions of older workers that existed among the informants. From these observations, we derive a more general perception of 'older workers'. The aim of this approach has been to accentuate the main features in the material (Thagaard 1999). In doing this, we have left out some of the data from the interviews; something that implies the constructed picture might have been different if other researchers had carried out this task. Whereas the construction of the general perceptions was primarily carried out by the first author, who did not participate in the interviews, the second author who had conducted nearly all the interviews gave input and suggested corrections after the perceptions were drawn up. By using this technique, we have combined analytical distance and nearness to the material in the process of analysis. We believe this has helped us find the balance between proximity and distance often referred to as challenging in qualitative research (Album 1996).

\section{Findings}

We have sorted most of the informants' descriptions under two major categories. First, perceptions of older workers on how they perform, such as abilities and limitations. Second, perceptions of older workers' roles, behavior or 'positioning' within the workplace. By 'positioning', we mean the roles they take, how they relate to and interfere with colleges and how they participate in the work environment and in the actual work at hand. Whereas the first category may be associated with a supply-side perspective, the latter category is clearly in line with a demand-side perspective because of its focus on the processes and interactions that take place at the workplace. However, since our ambition is to develop the demand-side perspective, we use both categories in order to better understand the perceptions, processes and actions at the workplace level (demand-side), rather than learn about older employees (supply-side). There were also experiences and perceptions that did not match any of these major categories, but since they were outliers and tended to point in various directions, we have left them out of further discussion in this article. We have summed up the findings with relevance for the two major categories in Table 1:

We found positive perceptions of older workers in all the 19 companies and branches covered, and negative perceptions in almost all companies (17). We found observations or perceptions suggesting some kind of 'positioning' in 10 of the companies. These companies represented all recruited branches except of bank/finance and industry/energy/ construction.

While positive perceptions of older workers were common in all companies and branches, the interviews reveal that the competence and experience of well-performing seniors seemed particular appreciated among informants from branches such as transport, church and research/technology. The included data further indicate more perceptions of resistance and trouble among older workers in health institutions and research organizations; however, this can be a coincidence since the number of companies and informants involved in this study is limited. With the exception of leaders and HRrepresentatives, who seem more often to describe challenges related to older workers than do union representatives, our data do not reveal any clear difference in perceptions between informant groups. We will now describe the findings more in detail. 
Table I Perceptions among employers and union representatives of older workers and the roles the play

\begin{tabular}{|c|c|}
\hline Perceptions of older workers & $\begin{array}{l}\text { Perceptions of the roles older workers play } \\
\text { in the work environment }\end{array}$ \\
\hline $\begin{array}{l}\text { Positive characteristics } \\
\text { - High competence } \\
\text { - High engagement } \\
\text { - High loyalty } \\
\text { - Social responsibility }\end{array}$ & $\begin{array}{l}\text { Some are 'chiefs' } \\
\text { - Has a lot of informal power } \\
\text { - Are 'rock-solid' in the workplace } \\
\text { - More outspoken } \\
\text { - Difficult to lead }\end{array}$ \\
\hline $\begin{array}{l}\text { Limitations } \\
\text { - Slower } \\
\text { - Low will to change } \\
\text { - More opposition } \\
\text { - Lack of understanding } \\
\text { - Little innovating } \\
\text { - Tired and worn-out }\end{array}$ & $\begin{array}{l}\text { Including chiefs } \\
\text { - Mentors, concern for the younger, tutors. } \\
\text { - Good leaders } \\
\text { Conflict generating chiefs } \\
\text { - Against any change } \\
\text { - Generates conflicts }\end{array}$ \\
\hline $\begin{array}{l}\text { Feelings more visible } \\
\text { - Afraid of doing something wrong } \\
\text { - Love for the job } \\
\text { - Proudness } \\
\text { - But also: little enthusiasm }\end{array}$ & $\begin{array}{l}\text { Some withdraw } \\
\text { - Little social participation } \\
\text { - Keep the 'private life' outside of the work sphere } \\
\text { Some seem to take no particular role, but are perceived } \\
\text { as individually different }\end{array}$ \\
\hline
\end{tabular}

\section{Workplace perceptions of older workers}

The list of positive perceptions is long and does not only contain perceptions of extremely well-functioning individuals but also of older workers in general. Several informants describe older workers as having high levels of expertise and knowledge based on long experience. For instance, a manager in a ferryboat company said, 'the old Captain knows how the wind that blows in his face while standing at the dock blows differently midsea and whether it is quiet or a storm on the other side of the sea, all at the same time'. Several of our informants described older workers as 'stable' and 'strong professionals', often with 'more loyalty' towards the job. 'Many of them take pride in their subject and have strong affiliation with the workplace. They have a great love for what they do and what they do for the company', one union representative (service and care sector) said. They were also often described as persons that take more social responsibility. A union representative (bank/finance sector) told us that seniors tended to manage leader-roles better than younger employees. These findings resemble and support those found in other studies such as those referred to in the background section of this paper.

Our informants have also experienced several limitations with older workers, and these perceptions also replicate the findings in previous studies that we referred to above. Examples are that older workers are perceived as working and acting more slowly than younger workers and that they are experienced as more sedate. 'The elderly slow down a little' (leader, bank/finance sector). They are also described as being less flexible and having less ability or willingness to adapt in new situations. Our informants gave several examples; 'some do not understand that they also need to change and develop' (leader, bank/finance sector) or 'the flexibility decreases when one becomes older' (leader, health 
sector). Some of the informants described what they viewed as a lack of innovation, understanding and insight among older workers: 'It is the older ones that I have to spend more time on to make them understand' (leader, health sector) one said, and a different leader in the same sector said 'some of them do not realize that they have lagged behind professionally' (leader, health sector). Some of the managers said they had experienced more resistance from older employees: 'Older people feel safer than younger to address things they do not agree with. The older they are, the safer they feel. The younger ask less questions' (leader, research/technology sector). While some leaders seemed to view such resistance as negative, these perceptions can also be understood as a positive perception of the older employees compared to younger ones.

Several informants described some of their older employees by using the Norwegian term 'slitenhet', which we have translated as 'tiredness'. This term refers to being tired, exhausted, fatigued, weary or worn out. For instance, one union representative (health sector) said that '.. they are tired from re-organizations, the new demands, insecurity. They are tired in their heads'. The informants described a physical form of tiredness among some seniors which they attributed to physical conditions in the workplace, physical stressors inflicted upon the body in the execution of the work or both at the same time. A different understanding of tiredness present among the informants refers to mental stressors that the employees had been exposed to over time, a kind of mental fatigue. In a quantitative analysis, Herlofsen and Hellevik (2019) found that older workers do not perceive themselves as more tired than younger. Nevertheless, the qualitative data displayed in this article shows that the perception that some older workers are 'tired' continues to exist among employers, and both HR and unionrepresentatives.

Another observation is also that employers describe older workers in terms of basing their actions more on feelings (emotions) as compared to younger workers. We found the following expressions: 'Older workers seem to base their actions more on feelings, while younger ones [rely] on facts' (leader, health), and 'older workers are more afraid of doing something wrong' (leader, merchandise/retail). We also found descriptions such as 'older workers tend to put their whole life into work' feeling a kind of love for and pride in work, and having a 'burning engagement' (leader, health). At the same time, some of our informants describe some older workers as being less enthusiastic about work than other employees are.

\section{Perceptions of older workers' roles or positioning in the work environment}

A different perception of older employees present in the data is the kind that describe roles or positioning in the work environment that older employees may take (e.g., as a 'chief'). These perceptions are more directly affiliated with a demand-side perspective since they address the interaction between individual workers and the workplace. This is also a topic that we have found little attention to in the international research literature on work and older workers, but that previously has been pointed to in a few Norwegian studies (Terjesen \& Salomon 2015).

A first major observation is that informants in different ways describe some seniors as informal 'chiefs' (in Norwegian described by the term 'høvdinger') who seem to play 
important roles in the work environment (in the eyes of the informants), and who hold a certain level of power attached to this position. For instance, some of the informants describe older workers as 'rock-solid' (in Norwegian described by the term 'bautaer'), as being more outspoken, and sometimes also as more difficult to control. One manager (research/technology) told us that when she hired some of the seniors on task-based consulting contracts after they had retired (instead of on regular employment contracts), this altered their power relations. In this process of retirement followed by later re-hiring as consultants, the seniors were deprived of their informal power.

Our data revealed two types of perceptions of 'chiefs': one positive and one negative. The positive one was described as a caring mentor, or as a safe and attentive base or coach, especially for younger colleagues. This type of perception can be illustrated by the following quote from a representative from the church: 'The older priests have tremendous expertise and can, for example, be used to guide younger pastors, even after retirement. We need older pastors, not least as good mentors for younger pastors'. A different informant (leader, merchandise/retail sector) said: 'An advantage of the elderly is that they can often act as "mothers" for the young (students) who work there' and added: '... they [old workers] are good sellers and they are good at developing good sellers'. (Leader, merchandise/retail sector)

The negative 'chief' was described as a stubborn fogy opposing any kind of change or development in the workplace, and often the cause of workplace conflicts. Examples of quotes that we related to this included this phrasing from a leader in the health sector: 'We face more resistance from the oldest and those who have been here the longest', while different example stems from a leader in the research/technology sector: 'some are "prima-donnas at 67". They do not function in the environment, they are conflict creators'.

The second major observation related to roles at the workplace was that some older workers tended to withdraw from the work environment. They were experienced as participating less in the social activities of the workplace and tried according to the informants to keep their private life separated from work. For instance, 'the younger ones are more around the clock. The elderly want more privacy' a union representative (research/ technology sector) said. 'The elderly are solid employees, but do not participate so much socially at work' (leader, transport sector).

The third major observation related to roles at the workplace was that most informants described older workers in general as a highly different group playing different roles based on individual preferences in more or less the same manner as other groups of employees. 'They are as different as everyone else, and they are worth gold; they have unique expertise and experience' one union representative in a transport company said. A leader in a research organization similarly said that ' $(t)$ here is no clear distinction between the youngest and the oldest. These are individual cases'.

Whereas some informants state that age is not relevant or that there are as many differences among older workers as there are between older and younger workers, descriptions of differences related to age are quite frequent in the data. For instance, a leader in a health institution had the following negative perception of older workers: 'The elderly are slower when it comes to changes. They function well in the job but oppose any change and new methods. They will not attend courses. The younger doctors have completely different values'. On the other hand, we also find several positive perceptions of being old versus young in working life:

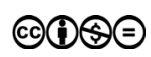


- 'Elderly people generally perform significantly better as leaders than younger ones'. (Union representative, bank/finance sector)

- 'The old people are more generous with their employer. The younger ones kick more at the little things'. (Leader, Church sector)

Both the total amount of data and some single quotes suggest that older workers are perceived as a heterogeneous group. 'The elders are very different' a different leader in a health institution said. Some quotes suggest that a perception of polarization also exists among some informants. For instance, a leader (research/technology sector) said that 'It is to a greater extent the elderly who "fall asleep" in the office, but they are also the most valuable, so this is very bipolar'. A union representative in the same company supported this leader: 'On one hand, [they are] those who represent some incredible resources (40 years in service and similar). On the other hand, they fell asleep 10 years ago'. (Union representative, research/technology sector). A quote from a different company within the same sector also illustrates this diversity and polarization: 'Some [older workers] are very talented - I have never worked with such talented people. But others are self-reliant and unwilling to change. The challenge is that they have to get out of the comfort zone, and that makes it especially difficult for the elderly. They must learn new ways of working but are less willing to do so'.

Direct expressions suggesting a presence of heterogeneity or polarization in the perceptions of the informants are rare in the data but occur in 5 of the 19 companies in our material. Whereas positive and negative perceptions or older workers and perceptions of positioning in the work environment thus are quite frequent and direct in our data, the presence of heterogeneity and polarization is a description or characteristic that we mainly extracted from our analysis of the total amount of perceptions.

\section{Brief summary}

Our major findings can be summed up this way: Seniors are perceived as individually different and as a heterogeneous group with both positive and negative qualities in line with other groups. Some positive and negative qualities are perceived as more typical for seniors.

Our findings and analysis thus not only support previous research in suggesting a heterogeneity in the group of older workers, but also seem to go further and suggest that employers, HR representatives and union representatives perceive processes of positioning in the work environment among older workers, and some perceive certain levels of polarization related to some older workers. Previous research has rarely addressed this issue.

\section{Discussion: Understanding employer behavior}

In this article, our main focus is not the actual characteristics or abilities of older employees, but rather how older employees are perceived at the workplace level, the possible work-place mechanisms behind such perceptions and what implications such perceptions may have on employer's willingness to hire or keep older workers. As the presentation of data above shows, we have found a long list of quite different observations and perceptions of old workers in the data, pointing in quite different directions. 
If we consolidate the many perceptions outlined above, we form a general impression of 'older workers' as a rather complex and divergent phenomenon or idea. The picture is neither consistently positive, nor consistently negative, but instead rather heterogeneous, mixed and in line with some studies in this research field (see for instance Henkens 2010; Kadefors \& Hanse 2012; Wainwright et al. 2018).

Previous research literature has pointed to a long range of factors located either within the individual, at the workplace, or in the community, that may have an influence on the employment and job retention of older workers. One such factor is employer perceptions. Several kinds of mechanisms contribute to form perceptions of older workers among employers. Previous literature has demonstrated that the presence of stereotypes, ageism and age discrimination are relevant. Some studies have pointed towards a need to develop more knowledge about interactions and processes that takes place at the workplace in order to better understand what contributes to form employer perceptions and their actions.

Our article adds new knowledge to this field by outlining workplace observations and perceptions in more detail, not from the dominating supply-side perspective, but from a workplace-oriented (demand-side) perspective. In addition to stereotypes, discrimination and ageism, our article suggests that workplace perceptions also stem from the observations of employers as well as union and HR-representatives and concrete experience of both how older workers interact with colleagues and the roles they take at the workplace. These observations indicate a possible presence of two kinds of mechanisms that may occur from time to time in workplaces; the mechanisms of positioning and polarization.

\section{Positioning}

As we have already shown, previous research has documented both positive and negative perceptions among leaders about older workers and how they perform at work. Some studies have also suggested that older workers may function well as mentors and often are more supportive towards younger colleges (Egdell et al. 2018; Kadefors \& Hanse 2012), and that because of this, actors at the workplace also perceive older workers as important in taking certain roles at the workplace.

Our study has also added to this field by revealing the presence of more workplace perceptions among leaders, union- and HR-representatives about what kind of roles older workers play in their workplaces. We have introduced the concept of 'positioning' to this field of research, and have found that some seniors from time to time are perceived as being positioned in the work environment in particular ways - both positive and negative - some of which represent a challenge for the workplace. These processes or mechanisms of positioning seem to be perceived as a something that develops over time as part of the interaction between older employees and their colleagues. Since such roles that older workers from time to time play seem to develop in a process of co-construction with colleagues and work environments (the local context), they are also something employers themselves can have an influence on and regulate, if they are able to recognize these processes and possess adequate competence and measures to deal with them.

The major contribution of our article therefore lies in providing knowledge about the presence of such perceptions among leaders, and both HR and union-representatives. 
Our data does only document the presence of such perceptions, and not of 'real' processes of positioning in Norwegian workplaces, as we have only studied the words and descriptions of leaders, HR- and union-representatives, and not the actual individual processes. However, we find it likely that the descriptions of our informants indicate a presence of also 'real' processes, at least to some extent. In order to document this, we would need a different research approach than the one we have used here. As these perceptions stem from concrete observations and experiences from what has happened at a workplace, we argue that these perceptions should not be understood as 'stereotypes'. Informants are clear that these roles and processes of positioning do not apply to the total group of older workers, but that such mechanisms may occur from time to time and affect some older workers.

\section{Polarization}

The major perception of older workers in our data is that of individual difference and heterogeneity; however, our data seem to suggest that individual differences (as perceived by employers, and HR and union-representatives) are something that develops across the work-life course. Keeping the whole dataset in mind, the informants seem to perceive employees as individuals who have increasingly developed their own individual style and characteristics as they have grown older and gained more experience and knowledge at work and in life in general. Our data suggest that older employees in general are perceived as a heterogeneous group, but some older individuals reside 'more in the extremes' on some topics. Whereas some older workers are perceived as highly qualified, valuable and vital for the company, others are perceived as rather outdated and sometimes difficult to manage. At the same time, the informants describe a tendency to withdraw among some older workers. We refer to this observation of possible increasing differences within the group of employees, as they grow older, as a perceived process or mechanism of polarization that may occur in companies from time to time. The process of polarization means that some older employees are perceived in a more positive and valuable way because they seem to keep learning and developing throughout their work career reaching ever higher levels of knowledge and competence. At the same time, other employees seem to withdraw from the work environment and active participation with their colleagues due to health issues, tiredness, lack of interest or other reasons. The differences when it comes to knowledge, competence, motivation and participation between employees as they grow older is perceived as increasing with growing age.

\section{Ambivalence towards older workers as a group}

The informants involved in this study have experienced highly competent and active seniors playing important and fruitful roles both as workers and as colleagues in the work environment. However, they have also experienced older workers who are tired, un-motivated, un-willing to adapt to the changes of work, and that withdraw from the work environment. While some seniors are perceived as powerful troublemakers, others are viewed as important resources with abilities and competences not present in their younger colleagues. While these perceptions of older employees certainly suggest that 
vital contributions may come from some senior workers and that there are good reasons to recruit and keep them, their experiences and perceptions also contain less productive versions of employees. Both perceptions of competent and clearly qualified as well as stubborn and contrary seniors exist among employers. Our lasting impression of these prevalent perceptions among leaders and HR and union-representatives included in this study therefore is one of ambivalence towards older workers as a group.

Based on such perceptions, one might expect little support for general measures and strategies aiming at job retention of older workers, such as for instance an extension of the retirement age on the national level, since such general measures may implicate less flexibility for employers and therefore are not in line with what they prefer. Vigtel's conclusion (2018) that risk-averse firms are more willing to hire senior workers when the retirement age is decreased supports this impression. Several other scholars also find a high degree of uncertainty and ambivalence among managers regarding the desirability and feasibility of extending working life (Martin et al. 2014; Wainwright et al. 2018). We believe therefore that our finding should be understood as a call for more flexible strategies towards older workers as a group. Our study therefore supports previous findings such as Martin et al. (2014) that call for flexible and creative approaches to policy and practices that acknowledge the heterogeneity of older workers.

The general impression of ambivalence among our informants seems to not only be related to perceptions of older workers as a group but also to how managers and leaders handle and meet seniors through their professional roles - in particular the more 'negative' cases - in inclusive and sustainable ways. As such, the ambivalence present implies a challenge for the managers. Viewed over some time the appearance of older workers who match these sometimes quite 'extreme' descriptions seems quite likely in companies with older employees based on these data. To a manager or a union representative, the 'polarized' and sometimes 'difficult' old worker represents a reality and something that they have to handle even though such 'extreme' cases may be rare and few in number. Handling older employees in adequate and respectful ways may require skillful managerial competence (Davies et al. 2018). An important task based on our analysis will be to equip future leaders and managers with the knowledge and competency to meet the challenges of an ageing work force. This includes how to deal with possible mechanisms of positioning and polarization within the workplace when they occur.

In order to address this challenge properly, the experiences and perceptions among employers and other workplace actors should not be discarded as 'stereotypes'. Although these perceptions clearly may be influenced by stereotypes such as those communicated through several channels (Kroon et al. 2018; Martin et al. 2014), we argue that these perceptions should rather be understood as possible starting points for collaboration and the development of sustainable age management in companies. Workplace perceptions stem from years of experience and observation, and can be understood as attempts of actors at the workplace level to express their challenges related to work retention of older workers. A future challenge for employers and internal/external support resources (HRM, employment and welfare services) will be to redefine workplace perceptions in ways that open up for development of flexible and sustainable policies and practices. This may implicate a need for increased awareness and ability in HRM-bodies to support managers in adequate ways, or via external support bodies such as those the Norwegian Work Life Centers exemplify.

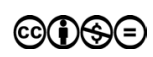




\section{Conclusion}

The major contribution of our article lies in providing more knowledge about perceptions among leaders, and both HR and union-representatives about older workers and their behavior in the workplace. This article suggests that workplace perceptions of older workers not only rest on stereotypes and ageism, but also on concrete experiences and observations of older workers. We have found that employers and both HR and union-representatives perceive older workers as a rather heterogeneous group, and that these informants relate the presence of certain processes or mechanisms of 'positioning' and polarization to some older workers from time to time. Our analysis suggests that these findings may indicate a feeling of ambivalence towards seniors as a group in Norwegian workplaces, and that this ambivalence may also implicate challenges for managers related to how to handle and cooperate with seniors in inclusive ways at the workplace.

Our data suggests that in order to meet the perceived challenges among managers and HR and union representatives related to handling what they experience as a heterogeneous and polarized ageing workforce, a future possibility within generous welfare states (such as the Nordics) may lie in developing and facilitating adequate forms of support for actors at the workplaces within this field. We also see a need to add further demand-side oriented research studies of barriers and possibilities within the workplace to the dominating supply-side focus within this field.

\section{References}

Album, D. (1996). Nære fremmede: pasientkulturen i sykehus [Near strangers. On the culture among patients at hospitals], Oslo, Tano.

Arvaja, M. (2016). Building teacher identity through the process of positioning, Teaching and Teacher Education 59: 392-402, doi: https://doi.org/10.1016/j.tate.2016.07.024.

Ayalon, L., \& Tesch-Römer, C. (2017). Taking a closer look at ageism: self-and other-directed ageist attitudes and discrimination, European Journal of Ageing 14 (1). doi: https://doi. org/10.1007/s10433-016-0409-9.

Blomé, M. W., Borell, J., Håkansson, C., \& Nilsson, K. (2018). Attitudes toward elderly workers and perceptions of integrated age management practices, International Journal of Occupational Safety and Ergonomics 1-9. doi: https://doi.org/10.1080/10803548.20 18.1514135 .

Bunge, M. (2004). How does it work? The search for explanatory mechanisms, Philosophy of the Social Sciences 34(2): 182-210. doi: https://doi.org/10.1177/0048393103262550.

Charmaz, K. (2006). Constructing Grounded Theory, SAGE.

Chiesa, R., Toderi, S., Dordoni, P., Henkens, K., Fiabane, E. M., \& Setti, I. (2016). Older workers: Stereotypes and occupational self-efficacy, Journal of Managerial Psychology 31(7): 1152-1166. doi: https://doi.org/10.1108/jmp-11-2015-0390.

Conen, W. S., Henkens, K., \& Schippers, J. (2012). Employers' attitudes and actions towards the extension of working lives in Europe, International Journal of Manpower 33(6): 648-665. doi: https://doi.org/10.2139/ssrn.2046974.

Davies, E. M., Van der Heijden, B. I., \& Stephenson, J. (2018). Are managers open to involvement in employee retirement? The influence of manager psycho-social characteristics, decision-making environment and older employee situational factors, Ageing \& Society 38(6): 1279-1301. doi: https://doi.org/10.1017/s0144686x17000022. 
Egdell, V., Maclean, G., Raeside, R., \& Chen, T. (2018). Age management in the workplace: manager and older worker accounts of policy and practice, Ageing \& Society 1-21. doi: https://doi.org/10.1017/s0144686x18001307.

Esping-Andersen, G. (1990). The Three Worlds of Welfare Capitalism, Cambridge: Polity Press.

Frøyland, K., Andreassen, T. A., \& Innvær, S. (2018a). Contrasting supply-side, demand-side and combined approaches to labour market integration, Journal of Social Policy 48(2): 311-328. doi: https://doi.org/10.1017/S0047279418000491.

Frøyland, K., Nordberg, T. H., \& Nedregård, O. (2018b). Nyere kunnskap om inkluderende arbeidsliv (IA). Sammenstilling og vurdering av studier med relevans for IA-avtalens mål og for et godt IA-arbeid, publisert i perioden 2014-2018 AFI-rapport (Vol. 2018, pp. 55) [New knowledge on inclusive work life. A literature review], Oslo: Arbeidsforskningsinstituttet, OsloMet.

Furunes, T., \& Mykletun, R. J. (2011). Do managers' perceptions coincide with established stereotyping of older workers' capabilities. Psychology of Stereotypes, New York: Nova Science Publishers, Inc, 173-192.

Gibbs, G. (2007). Analyzing Qualitative Data, London: SAGE.

Harris, K., Krygsman, S., Waschenko, J., \& Laliberte Rudman, D. (2017). Ageism and the older worker: A scoping review, The Gerontologist 58(2): e1-e14. doi: https://doi. org/10.1093/geront/gnw194.

Hedström, P., \& Ylikoski, P. (2010). Causal mechanisms in the social sciences, Annual Review of Sociology 36(1): 49-67, doi: https://doi.org/10.5040/9781474248785.ch-009.

Henkens, K. (2010). Stereotyping Older Workers and Retirement: The Managers' Point of View. Canadian Journal on Aging / La Revue canadienne du vieillissement, 24(4), 353-366, doi: https://doi.org/10.1353/cja.2006.0011.

Henkens, K., \& van Dalen, H. P. (2012). The Employer's Perspective on, The Oxford handbook of retirement, 215.

Henkens, K., van Dalen, H. P., Ekerdt, D. J., Hershey, D. A., Hyde, M., Radl, J., et al. (2017). What we need to know about retirement: Pressing issues for the coming decade, The Gerontologist 58(5): 805-812. doi: https://doi.org/10.1093/geront/gnx095.

Herlofson, K., \& Hellevik, T. (2019). Eldre i arbeidslivet - slitenhet og yrkesavgang. Søkelys på arbeidslivet, 36(4), 298-315. https://doi.org/10.18261/issn.1504-7989-2019-04-07 E.

Hermansen, Å. (2016). Retaining Older Workers (Vol. PhD), Oslo: Fafo.

Hvid, H. S., \& Falkum, E.e. (2019). Work and Wellbeing in the Nordic Countries. Critical Perspectives on the World's Best Working Lives: Routledge.

Ingold, J., \& Stuart, M. (2015). The Demand-Side of Active Labour Market Policies: A Regional Study of Employer Engagement in the Work Programme, Journal of Social Policy 44(3): 443-462, doi: https://doi.org/10.1017/S0047279414000890.

Kadefors, R., \& Hanse, J. J. (2012). Employers' attitudes toward older workers and obstacles and opportunities for the older unemployed to reenter working life, Nordic Journal of Working Life Studies 2(3): 29-47. doi: https://doi.org/10.19154/njwls.v2i3.2362.

Kroon, A. C., Van Selm, M., ter Hoeven, C. L., \& Vliegenthart, R. (2018). Reliable and unproductive? Stereotypes of older employees in corporate and news media, Ageing \& Society 38(1): 166-191. doi: https://doi.org/10.1017/s0144686x16000982.

LaPointe, K. (2010). Narrating career, positioning identity: Career identity as a narrative practice, Journal of Vocational Behavior 77(1): 1-9. doi: https://doi.org/10.1016/j. jvb.2010.04.003.

Martin, G., Dymock, D., Billett, S., \& Johnson, G. (2014). In the name of meritocracy: managers' perceptions of policies and practices for training older workers, Ageing \& Society 34(6): 992-1018. doi: https://doi.org/10.1017/s0144686x12001432.

Miles, M. B., Huberman, A. M., \& Saldaña, J. (2014). Qualitative data analysis: a methods sourcebook (3rd ed. ed.), Los Angeles: Sage. 
Ragin, C. C. (1987). The comparative method: moving beyond qualitative and quantitative strategies, Berkeley, California: University of California Press.

Salomon, R. H. (2012). Active Ageing in the Nordic Countries: Introduction, Nordic Journal of Working Life Studies 2(3): 1-6. doi: https://doi.org/10.19154/njwls.v2i3.2360.

Schulz, R. (2006). The Encyclopedia of Aging: 2-Volume Set: Springer Publishing Company.

Solem, P. E. (2016). Ageism and age discrimination in working life, Nordic Psychology 68(3): 160-175. doi: https://doi.org/10.1080/19012276.2015.1095650.

Taylor, P., \& Earl, C. (2016). The social construction of retirement and evolving policy discourse of working longer, Journal of Social Policy 45(2): 251-268. doi: https://doi. org/10.1017/s0047279416000581.

Terjesen, H. C. A., \& Salomon, R. H. (2015). Langsiktig ledelse: Om bærekraftig aldring i arbeidslivet. [Long term leadership. On sustainable ageing in work life] Oslo: Cappelen Damm Akademisk.

Thagaard, T. (1999). Systematikk og innlevelse. En innføring i kvalitativ metode. [Systematics and sensitivity. An introduction to qualitative methods], Bergen: Fagbokforlaget.

van Solinge, H., \& Henkens, K. (2017). Older workers' emotional reactions to rising retirement age: The case of the Netherlands, Work, Aging and Retirement 3(3): 273-283. doi: https://doi.org/10.1093/workar/wax010.

Vigtel, T. C. (2018). The retirement age and the hiring of senior workers, Labour Economics 51: 247-270. doi: https://doi.org/10.1016/j.labeco.2018.01.004.

Wainwright, D., Crawford, J., Loretto, W., Phillipson, C., Robinson, M., Shepherd, S., et al. (2018). Extending working life and the management of change. Is the workplace ready for the ageing worker, Ageing \& Society 1: 23. doi: https://doi.org/10.1017/s0144686 x18000569.

Yin, R. K. (2014). Case study research: design and methods (5th ed. ed.), Los Angeles, Calif: SAGE.

\section{Note}

${ }^{1}$ https://www.regjeringen.no/no/aktuelt/ny-ia-avtale-for-hele-arbeidslivet/id2622974/ (read 17.06.2019). 